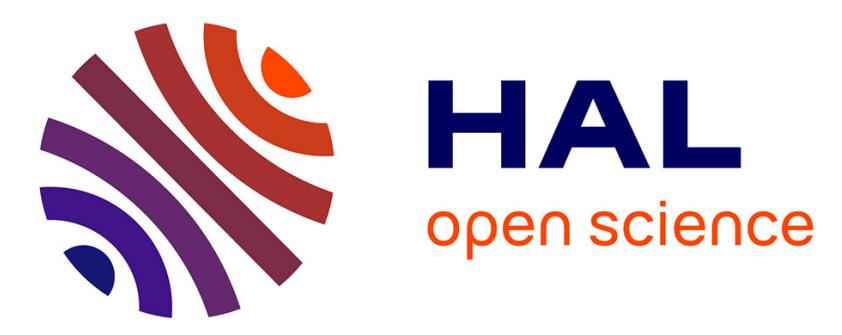

\title{
Drug-Initiated Synthesis of Cladribine-Based Polymer Prodrug Nanoparticles: Biological Evaluation and Structure Activity Relationships
}

Yinyin Bao, Elise Guegain, Julien Nicolas

\section{- To cite this version:}

Yinyin Bao, Elise Guegain, Julien Nicolas. Drug-Initiated Synthesis of Cladribine-Based Polymer Prodrug Nanoparticles: Biological Evaluation and Structure Activity Relationships. Reversible Deactivation Radical Polymerization: Materials and Applications, pp.201-217, 2018, 10.1021/bk-20181285.ch011 . hal-02348931

\section{HAL Id: hal-02348931 \\ https://hal.science/hal-02348931}

Submitted on 5 Nov 2019

HAL is a multi-disciplinary open access archive for the deposit and dissemination of scientific research documents, whether they are published or not. The documents may come from teaching and research institutions in France or abroad, or from public or private research centers.
L'archive ouverte pluridisciplinaire $\mathbf{H A L}$, est destinée au dépôt et à la diffusion de documents scientifiques de niveau recherche, publiés ou non, émanant des établissements d'enseignement et de recherche français ou étrangers, des laboratoires publics ou privés. 


\title{
Drug-Initiated Synthesis of Cladribine-Based Polymer Prodrug Nanoparticles: Biological Evaluation and Structure Activity Relationships
}

\author{
Yinyin Bao, Elise Guégain and Julien Nicolas* \\ Institut Galien Paris-Sud, CNRS UMR 8612, Univ Paris-Sud, Faculté de \\ Pharmacie, 5 rue Jean-Baptiste Clément, 92290 Châtenay-Malabry, France \\ *E-mail: julien.nicolas@u-psud.fr
}

\begin{abstract}
By using two reversible deactivation radical polymerization techniques, either nitroxide-mediated polymerization or reversible addition-fragmentation chain transfer polymerization, the "drug-initiated" approach was applied to cladribine $(\mathrm{CdA})$ as an anticancer drug to synthesize small libraries of well-defined and self-stabilized CdA-based polymer prodrug nanoparticles, differing from the nature and the molar mass of the grown polymer, and the nature of the linker between $\mathrm{CdA}$ and the polymer, thus allowing structurecytotoxicity relationships to be determined. Their biological evaluation was investigated in vitro on L1210 cancer cells. The preparation of fluorescent CdA-based nanoparticles with excellent imaging ability was also reported by applying the "drug-initiated" approach to an aggregation-induced emissionactive dye.
\end{abstract}

\section{RESERVE THIS SPACE}


Polymer prodrug nanocarriers have emerged as promising drug delivery systems that aim to circumvent the drawbacks of traditional drug-loaded nanocarriers (i.e., relying on a physical encapsulation of the drug into the polymer matrix) that usually exhibit significant limitations such as the "burst effect" and poor drug loadings. ${ }^{1,2}$ Polymer prodrug nanocarriers are obtained by covalent conjugation of drugs to a polymer chain by different approaches: (i) the post-functionalization of preformed polymers ("grafting to"); $;^{3-5}$ (ii) the polymerization of drug-conjugated monomers ("grafting through") ${ }^{6-10}$ and (iii) the polymerization from drug-conjugated initiators ("drug initiated" or "grafting from"). ${ }^{11}$ In all cases, the resulting polymer prodrugs can be formulated into narrowly dispersed and stable nanoassemblies in aqueous solution. Recently, our group further developed the "drug-initiated" approach and applied it to vinyl polymers by reporting on the design of a gemcitabine (Gem)-conjugated alkoxyamine $^{12}$ or chain transfer agent $(\mathrm{CTA})^{13,14}$ to prepare well-defined polymer prodrug nanoparticles by either nitroxide-mediated radical polymerization (NMP) of isoprene or reversible addition-fragmentation chain transfer (RAFT) polymerization of squalenyl methacrylate (SqMA), respectively. The resulting self-stabilized, Gem-polymer prodrug nanoparticles exhibited great colloidal stability and significant in vitro and in vivo anticancer activity. Nevertheless, to further confirm the robustness and the versatility of the "drug-initiated" method from reversible-deactivation radical polymerization (RDRP) techniques, it was then applied to cladribine (CdA, 2-chloro-2'deoxyadenosine) as another anticancer drug.

CdA, which can inhibit DNA synthesis, cause cell death and induce apoptosis, has been used as a first-line therapy in hairy cell leukemia and B-cell chronic lymphocytic leukemia. ${ }^{15-19}$ However, because of its rapid clearance from the bloodstream, $\mathrm{CdA}$ is administered at high doses, inducing cytotoxicity to resting and proliferating cells. ${ }^{20-22}$ Therefore, new strategies are needed to extend the circulation time and reduce the dose of CdA, as well as to induce higher toxicity to cancer cells compared to healthy cells.

In this context, we report on the synthesis of different series of CdA-based polymer prodrugs, either by NMP or RAFT polymerization (Figure 1). ${ }^{23,24}$ The impact of the chemical structure of the polymer prodrugs on the cytotoxicity of the corresponding nanoparticles to cancer cells was systematically investigated by comparing: (i) two different linkages between the drug and the polymer; (ii) two different polymers and (iii) different polymer chain lengths. It enabled the establishment of preliminary structure-cytotoxicity relationships. In addition, we also prepared fluorescent polymer prodrug nanoparticles by growing a welldefined polymer from a naphthalimide-based fluorophore with aggregationinduced emission (AIE) activity, ${ }^{25}$ which enabled the successful tracking of CdA-polymer prodrug nanoparticles in living cells by a co-nanoprecipitation process. $^{26}$ 


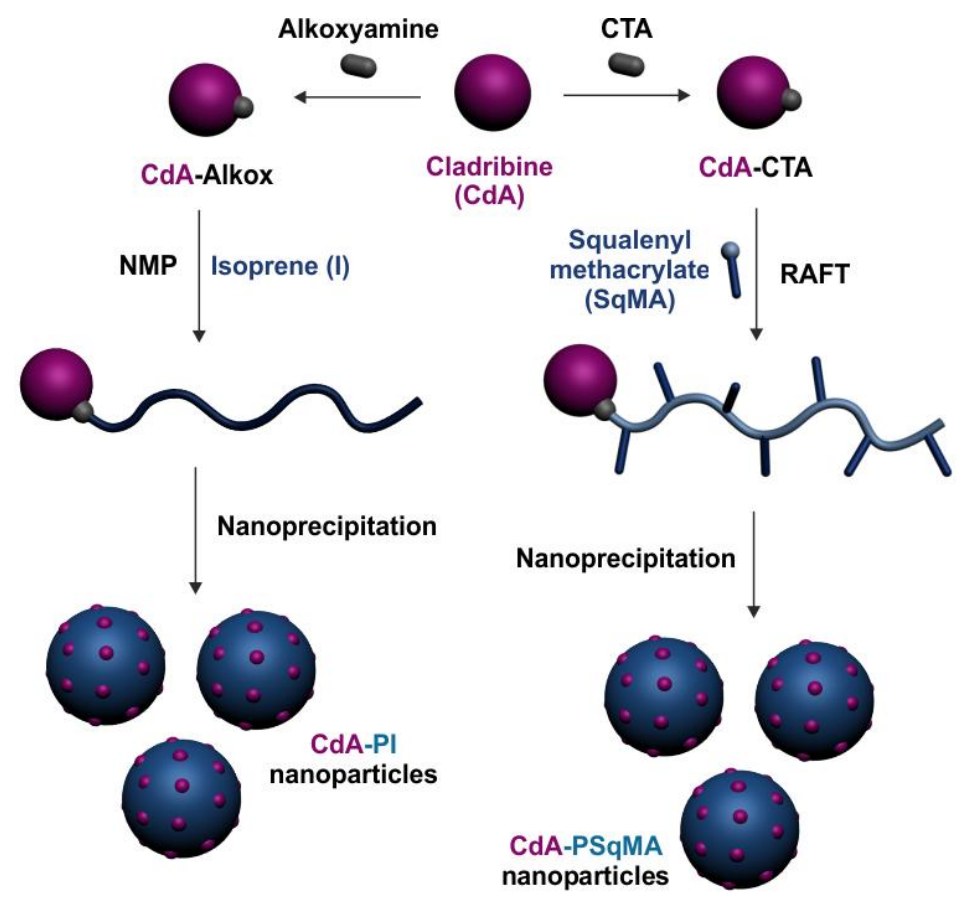

Figure 1. Synthesis of CdA-based polymer prodrug nanoparticles from "druginitiated" NMP of isoprene or RAFT polymerization of SqMA.

\section{Experimental Part}

\section{Materials}

Cladribine was purchased from Sequoia Research Products, Limited (U.K.). 4-Cyano-4-[(dodecylsulfanylthiocarbonyl)sulfanyl] pentanol (CDP) and 4cyano-4-[(dodecylsulfanylthiocarbonyl) sulfanyl]pentanoic acid (CDPA, 97\%) were obtained from Sigma-Aldrich. Diglycolic anhydride and tetra- $n$ butylammonium fluoride were purchased from Thermo Fisher Scientific (USA). SqMA was prepared according to published methods. ${ }^{13} \mathrm{~N}$-tert-Butyl- $\mathrm{N}-(1-$ diethyl phosphono-2,2-dimethylpropyl)nitroxide (SG1, 86\%) was kindly provided by Arkema. The AMA-SG1 (2-( $N$-tert-butyl- $N$-(1-diethoxyphosphoryl2,2-dimethylpropyl) aminoxy)propionic acid)alkoxyamine was prepared according to a published method. ${ }^{27}$ CdA-AMA-SG1, CdA-digly-AMA-SG1, digly-AMA-SG1, CdA-CDPA, CdA-digly-CDP, digly-CDP, and Napht-AMASG1 were prepared as reported elsewhere. ${ }^{23-26}$ LysoTracker Red was purchased 
from Life Technologies. Dulbecco's modified Eagle's medium (DMEM), fetal bovine serum (FBS) and human serum were purchased from Sigma (France). Penicillin was purchased from Lonza (Verviers, Belgium). All other materials were purchased from Sigma-Aldrich at the highest available purity and used as received.

\section{Synthesis}

Polymerization of isoprene from CdA-AMA-SG1. CdA-AMA-SG1 (55 mg, $0.075 \mathrm{mmol}$ ) was placed in a 15 -mL-capacity pressure tube (Ace Glass, Model 8648-164) fitted with plunger valves and thermowells. Isoprene $(0.75 \mathrm{~mL}, 7.5$ $\mathrm{mmol})$ and dioxane $(0.75 \mathrm{~mL})$ were added and the tube was subjected to three freeze-pump-thaw cycles, then backfilled with argon. The tube was placed in an oil bath at $115^{\circ} \mathrm{C}$ for $2 \mathrm{~h}$ (PI1), $8 \mathrm{~h}$ (PI2), or $16 \mathrm{~h}$ (PI3) and then cooled to room temperature by placing them in a cold-water bath. The residue was concentrated under reduced pressure to give $\mathrm{CdA}$-polyisoprene (PI) as a colorless product. Another polymerization was performed for $16 \mathrm{~h}$ with [isoprene $]_{0} /[\mathrm{CdA}$-AMASG1 $]_{0}=200 / 1$ (PI4).

Polymerization of isoprene from CdA-digly-AMA-SG1. CdA-digly-AMASG1 (54 mg, $0.06 \mathrm{mmol}$ ) was placed in a 15-mL-capacity pressure tube (Ace Glass, Model 8648-164) that was fitted with plunger valves and thermowells. Isoprene $(0.6 \mathrm{~mL}, 6.0 \mathrm{mmol})$ and dioxane $(0.6 \mathrm{~mL})$ were added, and the tubes were subjected to three freeze-pump-thaw cycles, then backfilled with argon. The tubes were placed in an oil bath at $115^{\circ} \mathrm{C}$ for $4 \mathrm{~h}$ (PI1d) or $16 \mathrm{~h}$ (PI2d) and then cooled to room temperature by placing them in a cold-water bath. The residue was concentrated under reduced pressure to give CdA-digly-PI as a colorless product. Two other polymerizations were performed for $16 \mathrm{~h}$ with $[\text { isoprene }]_{0} /[\text { CdA-digly-AMA }]_{0}=200 / 1$ (PI3d) and 400/1 (PI4d).

Polymerization of SqMA from CdA-CDPA. CdA-CDPA (31.8 mg, 0.04 mmol), AIBN (2.3 mg, $0.014 \mathrm{mmol})$, SqMA (0.11 g, $0.24 \mathrm{mmol})$ and dioxane $(0.75 \mathrm{~mL})$ were mixed together and equally distributed among four $7 \mathrm{~mL}$ glass vials. The solutions were degassed with argon bubbling for $30 \mathrm{~min}$. The tubes were placed in an oil bath at $70{ }^{\circ} \mathrm{C}$ for $0.5 \mathrm{~h}$ (PSq1), $1 \mathrm{~h}(\mathbf{P S q} 2), 2 \mathrm{~h}(\mathbf{P S q} 3)$ or $22 \mathrm{~h}$ (PSq4), and then cooled to room temperature by placing them in a coldwater bath. For each polymer, the residue was concentrated under reduced pressure and precipitated in cold $\mathrm{MeOH}$ to give protected CdA-PSqMA as a yellow viscous liquid.

Polymerization of SqMA from CdA-digly-CDP. CdA-digly-CDP (52.5 mg, $0.06 \mathrm{mmol})$, AIBN (1.2 mg, $0.007 \mathrm{mmol})$, SqMA (0.16 g, $0.36 \mathrm{mmol})$ and dioxane $(0.8 \mathrm{~mL})$ were mixed together and equally distributed among three 7 $\mathrm{mL}$ glass vials. The solutions were degassed with argon bubbling for $30 \mathrm{~min}$. The tubes were then placed in an oil bath at $70{ }^{\circ} \mathrm{C}$ for $1 \mathrm{~h}(\mathbf{P S q} 2 \mathrm{~d}), 4 \mathrm{~h}$ (PSq3d) 
and $30 \mathrm{~h}$ (PSq4d) and then cooled to room temperature by sinking them in a cold-water bath. For each polymer, the residue was concentrated under reduced pressure and precipitated in cold $\mathrm{MeOH}$ to give protected CdA-digly-PSqMA as a yellow viscous liquid. Another polymerization was performed for $4 \mathrm{~h}$ with $[\mathrm{SqMA}]_{0} /[\mathrm{CdA} \text {-digly-CDP }]_{0}=3 / 1$ (PSq1d).

Polymerization of isoprene from Napht-AMA-SG1. Napht-AMA-SG1 (38.7 $\mathrm{mg}, 0.056 \mathrm{mmol}$ ) was placed in a $15 \mathrm{~mL}$ capacity pressure tube (Ace Glass 8648-164) fitted with a plunger valve and a thermowell. Isoprene (PN1: $2.4 \mathrm{~mL}$, $23.1 \mathrm{mmol}$; PN2: $1.2 \mathrm{~mL}, 11.5 \mathrm{mmol}$ ) and dioxane (PN1: $2.4 \mathrm{~mL}$; PN2: $1.2 \mathrm{~mL}$ ) were added and the tube was subjected to three freeze-pump-thaw cycles, then backfilled with argon. The tube was placed in an oil bath at $115^{\circ} \mathrm{C}$ for $18 \mathrm{~h}$ and then cooled down to room temperature by placing the tube in a cold-water bath. The residue was concentrated under reduced pressure and precipitated in $\mathrm{MeOH}$ to give Napht-PI as a yellow viscous liquid.

Deprotection of TBDMS protected polymer prodrugs. TBDMS-protected CdA-PI, CdA-digly-PI, CdA-PSqMA, or CdA-digly-PSqMA (100 mg) was dissolved in $0.5 \mathrm{~mL}$ of THF, then tetra- $n$-butylammonium fluoride ( $1 \mathrm{M}$ in THF, $50 \mu \mathrm{L}$ ) was added and the solution continued to be stirred for $15 \mathrm{~min}$ before precipitation into $10 \mathrm{~mL}$ of $\mathrm{MeOH}$ and storage at $4{ }^{\circ} \mathrm{C}$ for $36 \mathrm{~h}$. The purified polymer was then collected by centrifugation, dried under high vacuum and analyzed by ${ }^{1} \mathrm{H}$ NMR and SEC. ${ }^{1} \mathrm{H}$ NMR analysis showed a complete disappearance of TBDMS protecting groups.

\section{Analytical Methods}

Nuclear magnetic resonance spectroscopy (NMR). NMR spectroscopy was performed in $5 \mathrm{~mm}$-diameter tubes in $\mathrm{CDCl}_{3}$ or DMSO- $\mathrm{d}_{6}$ at $25{ }^{\circ} \mathrm{C}$. ${ }^{1} \mathrm{H}$ and ${ }^{13} \mathrm{C}$ NMR spectroscopy was performed on a Bruker Avance 300 spectrometer at 300 $\mathrm{MHz}\left({ }^{1} \mathrm{H}\right)$ or $75 \mathrm{MHz}\left({ }^{13} \mathrm{C}\right)$. The chemical shift scale was calibrated on the basis of the internal solvent signals.

Mass spectrometry (MS). Mass spectra were recorded with a Bruker Esquire-LC instrument.

Size exclusion chromatography (SEC). SEC was performed at $30{ }^{\circ} \mathrm{C}$ with two columns from Polymer Laboratories (PL-gel MIXED-D; $300 \mathrm{~mm} \times 7.5 \mathrm{~mm}$; bead diameter $=5 \mathrm{~mm}$; linear part, 400 to $4 \times 10^{5} \mathrm{~g} \mathrm{~mol}^{-1}$ ) and a differential refractive index detector (SpectraSystem RI-150 from Thermo Electron Corp). The eluent was chloroform at a flow rate of $1 \mathrm{~mL} \mathrm{~min}^{-1}$ (Waters 515 pump) and toluene was used as a flow-rate marker. In the case of PI, the calibration curve was based on polystyrene (PS) standards (peak molar masses, $M_{\mathrm{p}}=162-523$ $000 \mathrm{~g} \mathrm{~mol}^{-1}$ ) from Polymer Laboratories. A PI calibration curve was constructed by converting the PS standard peak molecular weights $\left(M_{\mathrm{PS}}\right)$ to PI molecular weights $\left(M_{\mathrm{PI}}\right)$ using Mark-Houwink-Sakurada (MHS) constants determined for 
both polymers in $\mathrm{CCl}_{4}$ at $25^{\circ} \mathrm{C}$. For PI, the MHS constants used were $K_{\mathrm{PI}}=2.44$ $\times 10^{4}$ and $\alpha_{\mathrm{PI}}=0.712$. For PS, $K_{\mathrm{PS}}=7.1 \times 10^{4}$ and $\alpha_{\mathrm{PS}}=0.54(\mathrm{MW}<16700 \mathrm{~g}$ $\left.\mathrm{mol}^{-1}\right)$ or $K_{\mathrm{PS}}=1.44 \times 10^{4}$ and $\alpha_{\mathrm{PS}}=0.713\left(\mathrm{MW}>16700 \mathrm{~g} \mathrm{~mol}^{-1}\right){ }^{28}$ In the case of PSqMA, the calibration curve was based on polymethyl methacrylate (PMMA) standards (peak molar masses, $M_{\mathrm{p}}=625-625500 \mathrm{~g} \mathrm{~mol}^{-1}$ ) from Polymer Laboratories. This technique allowed the number-average molar mass $\left(M_{\mathrm{n}}\right)$, the weight-average molar mass $\left(M_{\mathrm{w}}\right)$ and the dispersity $\left(\nexists=M_{\mathrm{w}} / M_{\mathrm{n}}\right)$ to be determined.

Dynamic light scattering (DLS) and zeta potential. Nanoparticle diameters $\left(D_{z}\right)$ and zeta potentials $(\zeta)$ were measured by DLS with a Nano ZS from Malvern (scattering angle $=173^{\circ}$ ) at a temperature of $25^{\circ} \mathrm{C}$. The surface charge of the nanoparticles was investigated by $\zeta$-potential $(\mathrm{mV})$ measurement at $25^{\circ} \mathrm{C}$ after dilution with $1 \mathrm{mM} \mathrm{NaCl}$, using the Smoluchowski equation. For long-term colloidal stability studies, nanoparticles were stored at $4{ }^{\circ} \mathrm{C}$ between each measurement.

Cryogenic transmission electron microscopy (cryo-TEM). The morphology of the different nanoassemblies was examined by cryo-TEM. Briefly, $5 \mu \mathrm{L}$ of the nanoparticle suspension (5 mg mL $\mathrm{mL}^{-1}$ was deposited on a lacey formvar/carbon 300 mesh copper microscopy grid (Ted Pella). Most of the drop was removed with blotting filter paper and the residual thin film remaining within the holes was vitrified by plunging into liquid ethane. Samples were then observed using a JEOL Model 2100HC microscope.

Fluorescence spectroscopy. Emission spectra were obtained using a LS 50B fluorescence spectrometer from PerkinElmer. All measurements were conducted at room temperature $\left(\sim 25^{\circ} \mathrm{C}\right)$.

\section{Nanoparticle Preparation}

Nanoparticles were prepared by the nanoprecipitation technique. Unless otherwise mentioned, a final nanoparticle concentration of $2.5 \mathrm{mg} \mathrm{mL}^{-1}$ was targeted. Briefly, $2.5 \mathrm{mg}$ of polymer was dissolved in $0.5 \mathrm{~mL}$ of THF and added dropwise to $1 \mathrm{~mL}$ of MilliQ water under stirring. THF was then evaporated at room temperature using a Rotavapor (Buchi). Average diameter $\left(D_{z}\right)$ and zeta potential measurements were carried out in triplicate. For the conanoprecipitation of Napht-PI/CdA-digly-PI, $2.23 \mathrm{mg}$ of PI4d and $0.27 \mathrm{mg}$ of PN2 were dissolved in $0.5 \mathrm{~mL}$ of THF. A similar procedure was then applied. The resulting PN2/PI4d nanoparticles had a composition of $10.8 \mathrm{wt} . \%$ PN2 and 89.2 wt.\% PI4d, thus giving an overall drug loading of $5.3 \mathrm{wt} . \%$. 


\section{Biological Evaluations}

Cell lines and cell culture. The murine leukemia L1210 cells were kindly provided by Dr Lars Petter Jordheim (INSERM U590, Université Claude Bernard Lyon I, Lyon, France), and maintained as recommended. Briefly, L1210 cells were cultured in DMEM. All media were supplemented with $10 \%$ heat-inactivated $\mathrm{FBS}\left(56^{\circ} \mathrm{C}, 30 \mathrm{~min}\right)$ and penicillin $\left(100 \mathrm{U} \mathrm{mL}^{-1}\right)$. Cells were maintained under a humid atmosphere at $37{ }^{\circ} \mathrm{C}$ with $5 \% \mathrm{CO}_{2}$.

In vitro anticancer activity. MTT [3-(4,5-dimethylthiazol-2-yl)-2,5diphenyltetrazolium bromide] was used to test cytotoxicity of polymer prodrug nanoparticles and cell viability. Briefly, L1210 cells $\left(5 \times 10^{3}\right.$ per well $)$ were seeded in 96-well plates. After $1 \mathrm{~h}$ of incubation, cells were exposed to a series of different concentrations of polymer prodrug nanoparticles or free CdA for 72 h. After exposure, the medium was added with $20 \mu \mathrm{L}$ of MTT solution (5 mg $\mathrm{mL}^{-1}$ in PBS) to each well. The plates were incubated for $1 \mathrm{~h}$ at $37{ }^{\circ} \mathrm{C}$ and the medium was removed after centrifugation $\left(200 \mathrm{~g}, 5 \mathrm{~min}, 25^{\circ} \mathrm{C}\right) .200 \mu \mathrm{L}$ of DMSO were then added to each well to dissolve the formazan crystals. Absorbance was measured at $570 \mathrm{~nm}$ using a plate reader (Metertech $\Sigma$ 960, Fisher Bioblock, Illkirch, France). The percentage of surviving cells was calculated as the absorbance ratio of treated to untreated cells. The inhibitory concentration $50 \%$ (IC50) of the treatments was determined from the doseresponse curve. All experiments were set up in sextuplicate to determine means and SDs.

Cell imaging. L1210 cells were cultured on a coverslip in a culture dish for $24 \mathrm{~h}$ to achieve confluence. Cells were then incubated with the fluorescent nanoparticles at a concentration of $20 \mu \mathrm{g} \cdot \mathrm{mL}^{-1}$ at $37^{\circ} \mathrm{C}$ for $24 \mathrm{~h}$, then incubated with LysoTracker Red for $30 \mathrm{~min}$ under same incubation conditions. After treatment, the cells were washed with Dulbecco's phosphate buffered saline (PBS) and imaged using a confocal (SP8 TCS Leica, Germany) with a 63X/1.4 oil-immersion objective. The excitation wavelength was $405 \mathrm{~nm}$ and $543 \mathrm{~nm}$, and the fluorescence was collected in the range of 415-530 $\mathrm{nm}$ and 569-682 $\mathrm{nm}$, respectively. The pinhole diameter was set to 1 Airy Unit. 


\section{Results and Discussion}

\section{Design and Synthesis of CdA-Based Polymer Prodrugs}

Two different RDRP techniques (i.e., NMP or RAFT polymerization) were employed to prepare CdA-polymer prodrugs because of their well-known advantages in terms of simplicity and robustness to achieve well-defined functional polymers. Two CdA-bearing alkoxyamines and two CdA-bearing CTAs were synthesized, with either ester (linear or $\alpha$-methyl substituted) or diglycolate linkers in between the drug and the RDRP moiety (Figure 2). Because of the poor reactivity of the C- 6 amino group of CdA, the secondary hydroxyl group was selectively functionalized with the alkoxyamines or the RAFT agents, after protection of the primary hydroxyl group by tertbutyldimethylsilyl chloride (TBDMSCl). The functionalization was achieved by EDC/DMAP-assisted esterification with two SG1-based alkoxyamines (i.e., AMA-SG1 and digly-AMA-SG1) or two trithiocarbonates (4-cyano-4[(dodecylsulfanylthiocarbonyl) sulfanyl]pentanoic acid (CDPA) and diglycolate 4-cyano-4-[(dodecylsulfanylthiocarbonyl)sulfanyl]pentanol (digly-CDP)). To position a diglycolate linker in between the drug and the RDRP moiety to enhance the drug release kinetics, AMA-SG1 and CDP were previously reacted with diglycolic anhydride, giving digly-AMA-SG1 and digly-CDP. The coupling yields ranged from $47 \%$ to $91 \%$ (those with the diglycolate linker gave higher yields, likely because of a lower steric hindrance). 

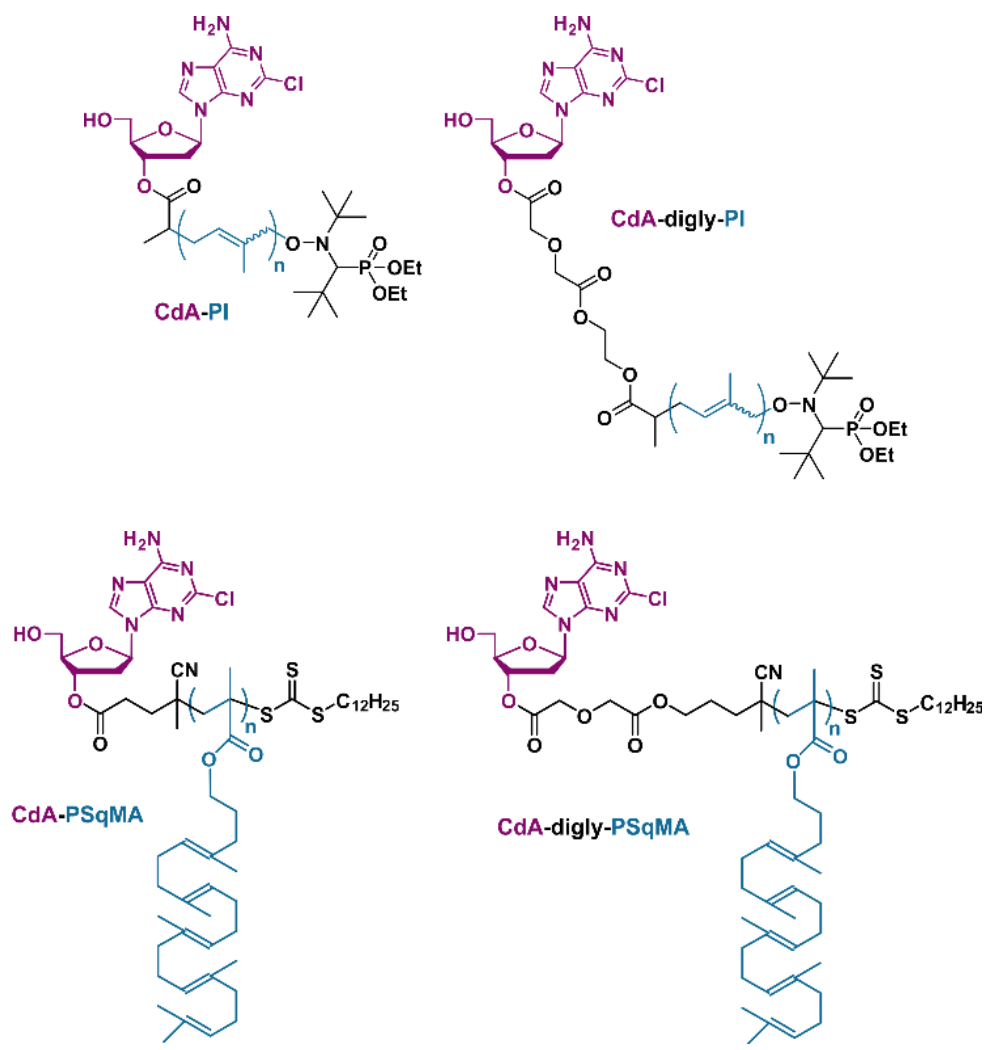

Figure 2. Structures of cladribine-polyisoprene (CdA-PI, PIx), cladribinediglycolate-polyisoprene (CdA-digly-PI, PIxd), cladribine-poly(squalenoyl methacrylate) (CdA-PSqMA, PSqx) and cladribine-diglycolate-poly(squalenoyl methacrylate) (CdA-digly-PSqMA, PSqxd).

Two different polymer promoieties, polyisoprene (PI) and poly(squalene methacrylate) (PSqMA), were selected. Given its chemical degradability, ${ }^{29}$ as well as its biocompatibility ${ }^{30}$ and its structural similarity with natural terpenoids, PI was chosen for the design of CdA-based polymer prodrugs by NMP. Because of the wide application of squalene $(\mathrm{Sq})$ as building block for the construction of molecular prodrugs, ${ }^{31,32}$ SqMA, ${ }^{13}$ a methacrylate monomer with a pendant squalene moiety was chosen for the design of CdA-based polymer prodrugs by RAFT polymerization. NMP of isoprene in presence of either CdA-AMA-SG1 or CdA-digly-AMA-SG1, was performed at $115^{\circ} \mathrm{C}$ in dioxane, followed by deprotection of TBDMS groups by tetra- $n$-butylammonium fluoride (TBAF) to give the CdA-PI (PIx, $x=1-4)$ and CdA-digly-PI (PIxd, $x=1-4$ ) conjugates, 
respectively (Figure 2). The RAFT polymerization of SqMA in presence of either CdA-CDPA or CdA-digly-CDP, was carried out in 1,4-dioxane at $70{ }^{\circ} \mathrm{C}$ with AIBN as the initiator, resulting in CdA-PSqMA (PSqx, $x=1-4)$ and CdAdigly-PSqMA (PSqxd, $\mathrm{x}=1-4$ ) prodrugs after similar deprotection, respectively (Figure 2).

By varying the polymerization time and/or the [monomer $]_{0} /[$ functionalized $\mathrm{CdA}]_{0}$ ratio, a library of well-defined CdA-based polymer prodrugs with variable chain lengths was obtained. Excellent control over the molecular weight of the polymers by both NMP and RAFT polymerizations was observed. The resulting polymerizations exhibited a linear relationship between monomer conversion and $M_{\mathrm{n}}$, with values close to theory. All polymer prodrugs were characterized by ${ }^{1} \mathrm{H}$ NMR and SEC, and the $M_{\mathrm{n}}$ ranged from $1420 \mathrm{~g} \mathrm{~mol}^{-1}$ to $4980 \mathrm{~g} \mathrm{~mol}^{-1}$, whereas CdA drug loading varied from $5.7 \mathrm{wt} . \%$ to $20.1 \mathrm{wt} . \%$. It should be noted that, the drug loading could easily be adjusted by changing the polymer chain length, one of the feature of the drug-initiated approach.

Table 1 Macromolecular and Colloidal Characteristics of CdA-PI, CdAdigly-PI, CdA-PSqMA and CdA-digly-PSqMA Polymer Prodrug Nanoparticles

\begin{tabular}{|c|c|c|c|c|c|c|c|}
\hline Expt. & $\begin{array}{c}M_{\mathrm{n}}{ }^{\mathrm{a}} \\
\left(\mathrm{g} \cdot \mathrm{mol}^{-1}\right)\end{array}$ & $D P_{\mathrm{n}, \mathrm{SEC}}^{\mathrm{b}}$ & $\oplus^{\mathrm{a}}$ & $\begin{array}{c}D_{\mathrm{z}}^{\mathrm{c}} \\
(\mathrm{nm})\end{array}$ & $\mathrm{PSD}^{\mathrm{c}}$ & $\begin{array}{c}\zeta^{\mathrm{d}} \\
(\mathrm{mV})\end{array}$ & $\begin{array}{l}\% \mathrm{CdA}^{\mathrm{e}} \\
(\mathrm{wt} . \%)\end{array}$ \\
\hline PI1 & 1420 & 12 & 1.17 & 167 & 0.06 & -69 & 20.1 \\
\hline PI2 & 1560 & 14 & 1.09 & 201 & 0.12 & -70 & 18.3 \\
\hline PI3 & 2270 & 24 & 1.15 & 152 & 0.08 & -64 & 12.6 \\
\hline PI4 ${ }^{f}$ & 2520 & 28 & 1.14 & 137 & 0.10 & -71 & 11.3 \\
\hline PI1d & 1470 & 10 & 1.10 & 143 & 0.07 & -66 & 19.4 \\
\hline PI2d & 1710 & 16 & 1.13 & 128 & 0.10 & -68 & 16.7 \\
\hline PI3d ${ }^{f}$ & 2960 & 34 & 1.17 & 127 & 0.08 & -70 & 9.6 \\
\hline PI4d $^{g}$ & 4980 & 64 & 1.20 & 111 & 0.11 & -66 & 5.7 \\
\hline PSq1 & 2710 & 4 & 1.18 & 69 & 0.14 & -51 & 10.5 \\
\hline PSq2 & 3080 & 5 & 1.16 & 82 & 0.11 & -54 & 9.3 \\
\hline PSq3 & 3420 & 6 & 1.17 & 94 & 0.11 & -58 & 8.3 \\
\hline PSq4 & 4040 & 7 & 1.12 & 94 & 0.09 & -61 & 7.1 \\
\hline PSq1d $^{h}$ & 2920 & 4 & 1.25 & 112 & 0.12 & -62 & 9.8 \\
\hline PSq2d & 3090 & 5 & 1.25 & 107 & 0.14 & -60 & 9.2 \\
\hline PSq3d & 3310 & 6 & 1.27 & 96 & 0.12 & -54 & 8.6 \\
\hline PSq4d & 4470 & 8 & 1.27 & 84 & 0.10 & -53 & 6.4 \\
\hline
\end{tabular}




\section{Formulation and Colloidal Characteristics of the Nanoparticles}

CdA-based polymer prodrug nanoassemblies were prepared by nanoprecipitation of a THF solution of the different CdA-based polymer prodrugs into water, targeting a final concentration of $2.5 \mathrm{mg} \mathrm{mL}^{-1}$. As shown in Table 1, the nanoparticles exhibited an average diameters in the 70-200 nm range and narrow particle size distributions $(\mathrm{PSD}=$ ca. 0.1$)$ as measured by DLS. Representative Cryo-TEM images of each type of nanoparticles showed spherical morphologies and colloidal characteristics in good agreement with DLS data (Figure 3).
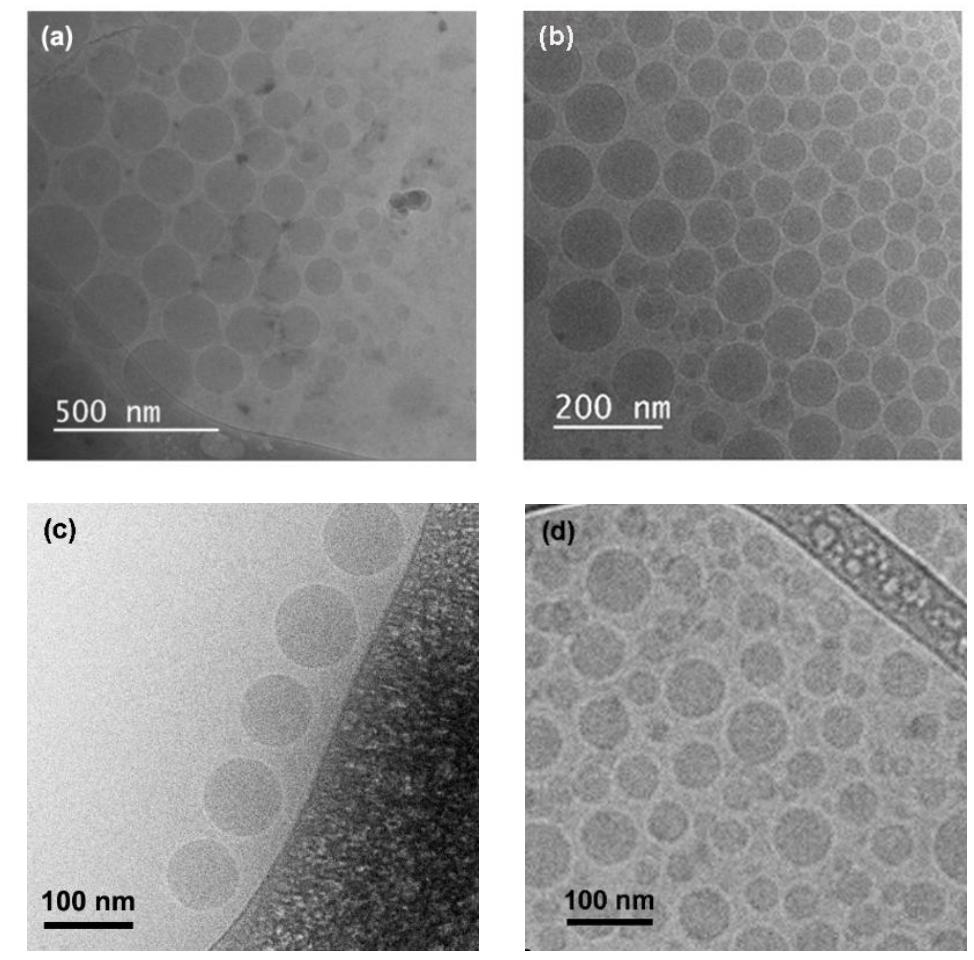

Figure 3. Cryo-TEM images of: (a) CdA-PI PI3, (b) CdA-digly-PI PI4d, (c)CdA-PSqMA PSq1 and (d) CdA-digly-PSqMA PSq1d nanoparticles.

The colloidal characteristics of the different polymer prodrug nanoparticles were then monitored at room temperature with time; from 3 weeks to 3 months. As shown in Figure 4, they all exhibited very high colloidal stability in water in terms of average diameter and particle size distribution. The high stability is likely the result of an efficient electrostatic stabilization provided by the strongly 
negative surface charges (from $-70 \mathrm{mV}$ to $-50 \mathrm{mV}$ ) of the different nanoparticles, as shown by zeta potential measurements (Table 1). Interestingly, the average diameter can be accurately tuned by varying the polymer chain length: the longer the chain length, the smaller the diameter. With CdA-digly-PI for example, the average diameter decreased from $143 \mathrm{~nm}$ to $111 \mathrm{~nm}$ along with increasing the $M_{\mathrm{n}}$ from $1470 \mathrm{~g} \mathrm{~mol}^{-1}$ to $4980 \mathrm{~g} \mathrm{~mol}^{-1}$ (PI1d-PI4d) (Table 1). This trend could be assigned to an increasing compaction of the polymer chains when the $M_{\mathrm{n}}$ is increased because of increased hydrophobic interactions and lower solubility.
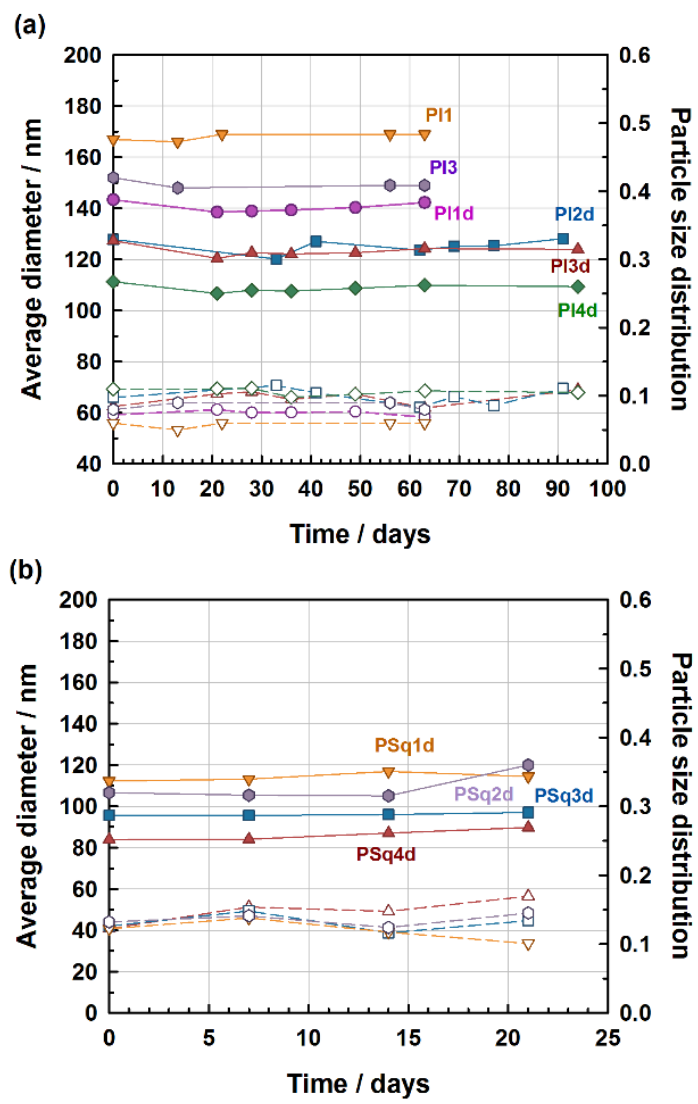

Figure 4. Evolution with time of the average diameter (solid symbols) and the particle size distribution (open symbols) determined by DLS of: (a) CdA-PI (PII and PI3) and CdA-digly-PI (PIId-PI4d) nanoparticles and (b) CdA-diglyPSqMA (PSq1d-PSq4d) nanoparticles. 


\section{In Vitro Anticancer Activity}

The in vitro cytotoxic activity of the different polymer prodrug nanoparticles was then investigated by cell viability assay (MTT) on a murine leukemia (L1210) cell line (see Figure 5). On one hand, CdA-PI nanoparticles did not show any cytotoxicity up to $10 \mu \mathrm{M}$, even when the incubation time was increased from 3 days to 5 days, whereas CdA-digly-PI nanoparticles (PI1d-PI4d) with $M_{\mathrm{n}}$ ranging from $1470 \mathrm{~g} \cdot \mathrm{mol}^{-1}$ to $4980 \mathrm{~g} . \mathrm{mol}^{-1}$ led to significant cytotoxicity (Figure 5a) with half maximal inhibitory concentrations (IC50) varying between $660 \mathrm{nM}$ and $1430 \mathrm{nM}$. These results are in line with the drug release profiles of the different CdA-based prodrugs ${ }^{23,24}$ and also with previous literature about small CdA prodrug molecules. ${ }^{33,34}$ The nanoparticles from control polymer AMA-digly-PI (PIOd) $\left(M_{\mathrm{n}}=2650 \mathrm{~g} \mathrm{~mol}^{-1}\right)$ didn't give any cytotoxicity up to at least $\sim 6 \mu \mathrm{M}$. On the other hand, all PSqMA-based prodrug nanoparticles exhibited from moderate to significant anticancer acitivity (Figure 5b). For instance, CdA-digly-PSqMA nanoparticles PSq1d, PSq3d and PSq4d $\left(M_{\mathrm{n}}=2920,3310\right.$ and $4470 \mathrm{~g} \cdot \mathrm{mol}^{-1}$, respectively) gave IC50 values regularly decreasing from 2.17 to $1.36 \mu \mathrm{M}$. However, the cytotoxicity of CdA-PSqMA nanoparticles was much lower than that of CdA-digly-PSqMA. PSq1, PSq3 and PSq4 $\left(M_{\mathrm{n}}=2710,3420\right.$ and 4040 g.mol ${ }^{-1}$, respectively $)$ indeed showed IC50 values gradually ranging from $4.1 \mu \mathrm{M}$ to $8 \mu \mathrm{M}$. 

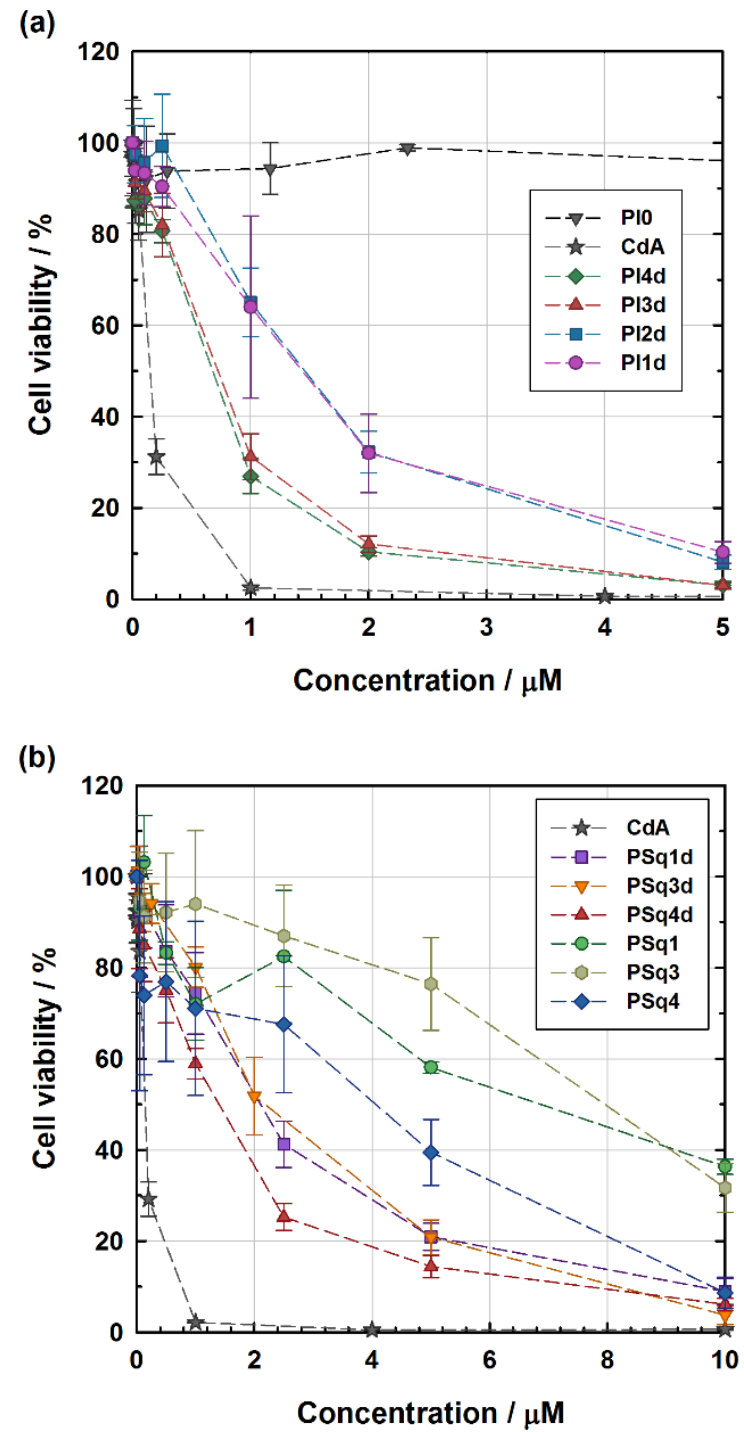

Figure 5. Viability assay (MTT test) on L1210 cells with increasing concentrations of: (a) CdA-digly-PI nanoparticles PIId-PI4d and PIO (AMAdigly-PI) and free CdA and (b) CdA-digly-PSqMA nanoparticles PSq1d, PSq3d and PSq4d, CdA-PSqMA nanoparticles PSq1, PSq3 and PSq4 and free CdAs. 
CdA-based polymer prodrug nanoparticles showed higher IC50 values than free CdA (IC50 = $145 \mathrm{nM}$ ), because of their prodrug nature, but high cytotoxicity to cancer cells was still obtained. Interestingly, for both of PI- and PSqMA-based systems, IC50 values decreased with increasing the polymer chain length (Figure 5). Several parameters are known to strongly influence the cellular uptake of the nanoparticles by cancer cells (and eventually the cytotoxicity), such as their average size and the composition of their corona. Whereas smaller nanoparticles usually give a better internalization in cancer cells, increasing the polymer chain length is likely to result in more hydrophobic nanoparticle surfaces, leading to a different protein adsorption pattern, and eventually change the nanoparticle uptake by cancer cells. ${ }^{35,36}$ From all these results, a structure-cytotoxicity relationship was then established (Table 2). A decrease of cytotoxicity to cancer cells was observed in the following order: CdA-digly-PI > CdA-digly-PSqMA > CdA-PSqMA > CdA-PI (data for CdAPI was not plotted because no cytotoxicity was obtained). Not only this can be assigned to the lability of the linker (diglycolate > linear ester > methylsubstituted ester), but also to the nature of the monomer used (CdA-digly-PI > CdA-digly-PSqMA). Indeed, PI chains are likely to provide less steric hindrance than bulky PSqMA chains, thus giving more accessibility for the cleavage to proceed.

Table 2 Evolution of the $\mathrm{IC}_{50}$ as Function of the Nature and the $M_{\mathrm{n}}$ of the CdA-Based Polymer Prodrug. ${ }^{a}$

\begin{tabular}{ccc}
\hline Expt. & $M_{\mathrm{n}}\left(\mathrm{g} \cdot \mathrm{mol}^{-1}\right)$ & $\begin{array}{c}\mathrm{IC}_{50} \\
(\mu \mathrm{M})\end{array}$ \\
\hline \multirow{2}{*}{ CdA-PI } & n.d. & n.d. \\
& 4470 & 1.36 \\
\multirow{2}{*}{ CdA-digly-PI } & 3310 & 2.20 \\
& 2920 & 2.17 \\
\hline \multirow{2}{*}{ CdA-PSqMA } & 4040 & 4.10 \\
& 3420 & 7.0 \\
\multirow{2}{*}{ CdA-digly-PSqMA } & 2710 & 8.0 \\
& 4980 & 0.66 \\
& 2960 & 0.72 \\
& 1710 & 1.43 \\
\hline
\end{tabular}

${ }^{a}$ Note that CdA-PI is not represented because the $\mathrm{IC}_{50}$ was impossible to determine because of absence of CdA release. 


\section{Fluorescence Imaging in Living Cells}

To study the subcellular localization of CdA-based polymer nanoparticles in living cells, a fluorescent polymer (Napht-PI PN2, $M_{\mathrm{n}}=3700 \mathrm{~g} \cdot \mathrm{mol}^{-1}, D=$ $1.15)^{26}$ exhibiting aggregation-induced emission (AIE) activity ${ }^{25}$ was synthesized following a similar strategy and co-nanoprecipitated with CdAbased polymer prodrugs. L1210 cells were then incubated with fluorescent nanoparticles obtained by the co-nanoprecipitation of PN2 and PI3d. As shown in Figure 6, a bright green fluorescence signal from the nanoparticles (green channel, $500-560 \mathrm{~nm}, \lambda_{\text {ex }}=408 \mathrm{~nm}$ ) was observed in L1210 cells, which indicated the efficient internalization of the nanoparticles into the cells. The presence of the nanoparticles in the lysosomes was confirmed by a yellow colocalization observed after overlaying the green channel with the red channel (staining of the lysosomes, 569-682 nm, $\lambda_{\mathrm{ex}}=543 \mathrm{~nm}$ ) (Figure 6d), which suggested an endocytosis mechanism. Importantly, cytotoxicity to cancer cells was maintained as shown by MTT assay (whereas pure PN2 nanoparticles were not toxic to cells). ${ }^{26}$ This general strategy enabled the facile production of AIE dye-based polymers for nanoparticle labeling by simple co-nanoprecipitation with drug-polymer conjugates. 

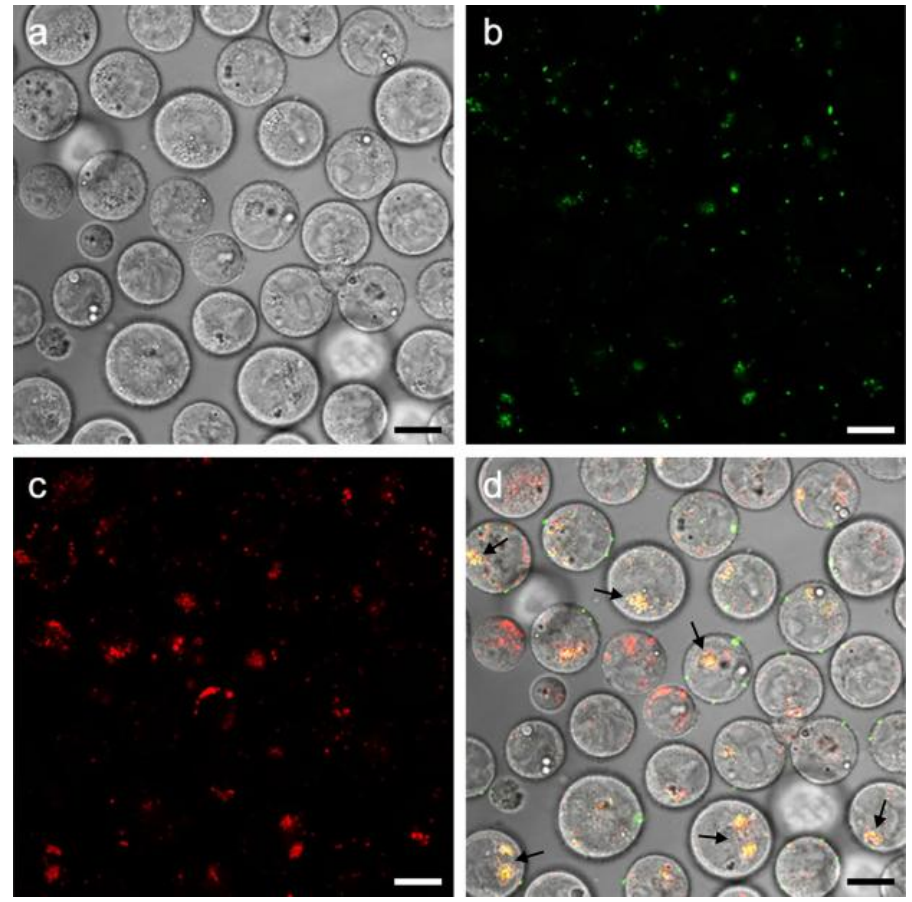

Figure 6. L1210 cells Normarski image (a), confocal microscopy images [green channel (Napht, b), red channel (LysoTracker Red, c)] and merge of red and green fluorescence images with Nomarski image (d) after a $24 \mathrm{~h}$ incubation of L1210 cells with AIE-active polymer prodrug nanoparticles (PI3d/PN2, 1 wt.\% of Napht-OH). Scale bars $=20 \mu \mathrm{m}$. Arrows indicate colocalization.

\section{Conclusion}

Different libraries of CdA-based polymer prodrugs were successfully synthesized by the "drug-initiated" method via either NMP of isoprene or RAFT polymerization of a methacrylic ester bearing a naturally occurring isoprenoid moiety. The formed nanoparticles obtained by nanoprecipitation exhibited great colloidal stability in aqueous solution and in vitro cytotoxicity to cancer cells governed by their structural parameters. With the help of fluorescent nanoparticles from AIE-dye-initiated polymerization, the subcellular localization of CdA-based polymer nanoparticles was also successfully imaged in living cells. This study opens new perspectives for the design of a broad range of novel drug-initiated polymer prodrug nanocarriers by changing the nature of the drug, the linker and the polymer. 


\section{Acknowledgments}

This work is supported by Marie Curie Intra-European Fellowship (YB) from European Commission (No. 623501). The authors thank Julie Mougin (Institut Galien Paris-Sud) for technical assistance in HPLC and cryo-TEM (Service de Microscopie Electronique, UFR de Biologie Intégrative, Université Paris-Sud), Valérie Nicolas (Institut Paris-Sud d'Innovation Therapeutique (IPSIT), Université Paris-Sud) for technical assistance in confocal imaging, Stéphanie Denis (Institut Galien Paris-Sud) for technical assistance in cell culture and Stéphanie Nicolaÿ for mass spectrometry analyses (Service d'Analyses des Médicaments et Métabolites, Institut Paris-Sud d'Innovation Therapeutique (IPSIT), IFR 141, Université Paris-Sud). CNRS and University Paris-Sud are also acknowledged for financial support.

\section{Reference}

1. Khandare, J.; Minko, T. Prog. Polym. Sci. 2006, 31, 359-397.

2. Delplace, V.; Couvreur, P.; Nicolas, J. Polym. Chem. 2014, 5, 1529-1544.

3. Bae, Y.; Fukushima, S.; Harada, A.; Kataoka, K. Angew. Chem., Int. Ed. 2003, 42, 4640-4643.

4. Du, J.-Z.; Du, X.-J.; Mao, C.-Q. ; Wang, J. J. Am. Chem. Soc. 2011, 133, 17560-17563.

5. Aryal, S.; Hu, C.-M. J.; Zhang, L. ACS Nano, 2009, 4, 251- 258.

6. Hu, X.; Hu, J.; Tian, J.; Ge, Z.; Zhang, G.; Luo, K.; Liu, S. J. Am. Chem. Soc. 2013, 135, 17617-17629.

7. Hasegawa, U.; van der Vlies, A. J.; Wandrey, C.; Hubbell, J. A. Biomacromolecules, 2013, 14, 3314-3320.

8. Khan, A. R.; Magnusson, J. P.; Watson, S.; Grabowska, A. M.; Wilkinson, R. W.; Alexander, C.; Pritchard, D. Polym. Chem. 2014, 5, 5320-5329.

9. Gao, A. X.; Liao, L.; Johnson, J. A. ACS Macro Lett. 2014, 3, 854-857.

10. Liu, J.; Liu, W.; Weitzhandler, I.; Bhattacharyya, J.; Li, X.; Wang, J.; Qi, Y.; Bhattacharjee, S.; Chilkoti, A. Angew. Chem., Int. Ed. 2015, 54, 10021006.

11. Nicolas, J. Chem. Mater. 2016, 28, 1591-1606.

12. Harrisson, S.; Nicolas, J.; Maksimenko, A.; Bui, D. T.; Mougin, J.; Couvreur, P. Angew. Chem., Int. Ed. 2013, 52, 1678-1682.

13. Trung Bui, D.; Maksimenko, A.; Desmaele, D.; Harrisson, S.; Vauthier, C.; Couvreur, P.; Nicolas, J. Biomacromolecules 2013, 14, 2837-2847.

14. Maksimenko, A.; Bui, D. T.; Desmaele, D.; Couvreur, P.; Nicolas, J. Chem. Mater. 2014, 26, 3606-3609. 
15. Piro, L.; Carrera, C.; Beutler, E.; Carson, D. Blood 1988, 72, 1069-1073.

16. Juliusson, G.; Liliemark, J. Lancet 1993, 341, 54.

17. Leoni, L. M.; Chao, Q.; Cottam, H. B.; Genini, D.; Rosenbach, M.; Carrera, C. J.; Budihardjo, I.; Wang, X.; Carson, D. A. Proc. Natl. Acad. Sci. U. S. A. 1998, 95, 9567-9571.

18. Robak, T. Curr. Treat. Options Oncol. 2006, 7, 200-212.

19. Robak, T.; Wierzbowska, A. Leuk. Res. 2014, 38, 425-427.

20. Vinogradov, S. V. Expert Opin. Drug Delivery 2007, 4, 5-17.

21. Betticher, D. C.; Fey, M. F.; von Rohr, A.; Tobler, A.; Jenzer, H.; Gratwohl, A.; Lohri, A.; Pugin, P.; Hess, U.; Pagani, O.; Zulian, G.; Cerny, T. Ann. Oncol. 1994, 5, 57-64.

22. Dmoszyska, A.; Legiec, W.; Wach, M. Leuk. Lymphoma 1999, 34, 335-340.

23. Bao, Y.; Boissenot, T.; Guégain, E.; Desmaële, D.; Mura, S.; Couvreur, P.; Nicolas, J. Chem. Mater. 2016, 28, 6266-6275.

24. Bao. Y.; Nicolas, J. Polym. Chem. 2017, 8, 5174-5184.

25. Bao, Y.; De Keersmaecker, H.; Corneillie, S.; Yu, S.; Mizuno, H.; Zhang, G.; Hofkens, J.; Mendrek, B.; Kowalczuk, A.; Smet, M. Chem. Mater. 2015, 27, 3450-3455.

26. Bao. Y.; Guégain, E.; Nicolas, V.; Nicolas, J. Chem. Commun. 2017, 53, 4489-4492.

27. Guégain, E.; Delplace, V.; Trimaille, T.; Gigmes, D.; Siri, D.; Marque, S.; Guillaneuf, Y.; Nicolas, J. Polym. Chem. 2015, 6, 5693-5704.

28. Harrisson, S.; Couvreur, P.; Nicolas, J. Macromolecules 2011, 44, 92309238.

29. Cheng, C.; Qi, K.; Khoshdel, E.; Wooley, K. L. J. Am. Chem. Soc. 2006, $128,6808-6809$.

30. Yang, H.-C.; Silverman, J.; Wozniak, J. J. Low temperature heat shrinkable polymer material. U.S. Patent 4,596,728, June 24, 1986.

31. Couvreur, P.; Stella, B.; Reddy, L. H.; Hillaireau, H.; Dubernet, C.; Desmaële, D.; Lepêtre-Mouelhi, S.; Rocco, F.; Dereuddre-Bosquet, N.; Clayette, P.; Rosilio, V.; Marsaud, V.; Renoir, J.-M.; Cattel, L. Nano Lett. 2006, 6, 2544-2548.

32. Bekkara-Aounallah, F.; Gref, R.; Othman, M.; Reddy, L. H.; Pili, B.; Allain, V.; Bourgaux, C.; Hillaireau, H.; Lepetre-Mouelhi, S.; Desmaele, D.; Nicolas, J.; Chafi, N.; Couvreur, P. Adv. Funct. Mater. 2008, 18, 37153725.

33. Grieb, P.; Kryczka, T.; Wojtowicz, R.; Kawiak, J.; Kazimierczuk, Z. Acta Biochim. Polym. 2002, 49, 129-137.

34. Kryczka, T.; Stachnik, K.; Kozlowska, M.; Kazimierczuk, Z.; Hovinen, J.; Chrapusta, S. J.; Grieb, P. Acta Polym. Pharm. 2005, 62, 411-415. 
35. Monopoli, M. P.; Aberg, C.; Salvati, A.; Dawson, K. A. Nat. Nanotechnol. 2012, 7, 779-786.

36. Blanco, E.; Shen, H.; Ferrari, M. Nat. Biotechnol. 2015, 33, 941-951. 